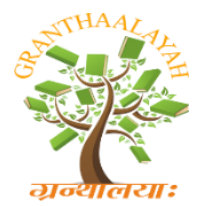

\author{
INTERNATIONAL JOURNAL OF RF
GRANTHAALAYAH \\ A knowledge Repository
}

DOI: https://doi.org/10.29121/granthaalayah.v7.i10.2019.401

Science

\title{
CHARACTERISTICS OF FUNCTIONAL INDICATORS OF ENGINEERING PROJECTS
}

\author{
Ing. Jan Lhota *1, Doc. Ing. Theodor Beran, Ph.D ${ }^{2}$ \\ ${ }^{* 1,2}$ Czech Technical University in Prague - Faculty of Mechanical Engineering; Technická 4, \\ 16607 Prague 6, Czech Republic
}

\begin{abstract}
Engineering or product development is one of the most important parts of the automotive industry because the development phase could be adjusted a lot of technical and economic parameters. Most of the engineering companies want to achieve better profit and sales, but in our globalized and digitalized world is this goal the more and more difficult to achieve. With the development of computers, on the one hand, the processes associated with project evaluation and the ability to manage them effectively have been simplified, but on the other hand, the Internet network creates a virtual space where activities with long-distance can be carried out quickly and efficiently. This pressure on engineering companies and their competitiveness are greatly jeopardized. For this reason, it is important to focus on the characteristics of project management plans and the possibilities of eliminating risk factors.
\end{abstract}

Keywords: Engineering; Projects; Planning; Project Management; Automobile Industry.

Cite This Article: Ing. Jan Lhota, and Doc. Ing. Theodor Beran. (2019). "CHARACTERISTICS OF FUNCTIONAL INDICATORS OF ENGINEERING PROJECTS." International Journal of Research - Granthaalayah, 7(10), 348-361. 10.29121/granthaalayah.v7.i10.2019.401.

\section{Introduction}

The main project development forecasts starting point for the process of the development of projects or its individual parts is the analysis of the past development and the current state of the analyzed object. However, it is necessary to submit and analyze some development proposals. The analysis of activities and functions of the object is one of the main elements of the development programs. 


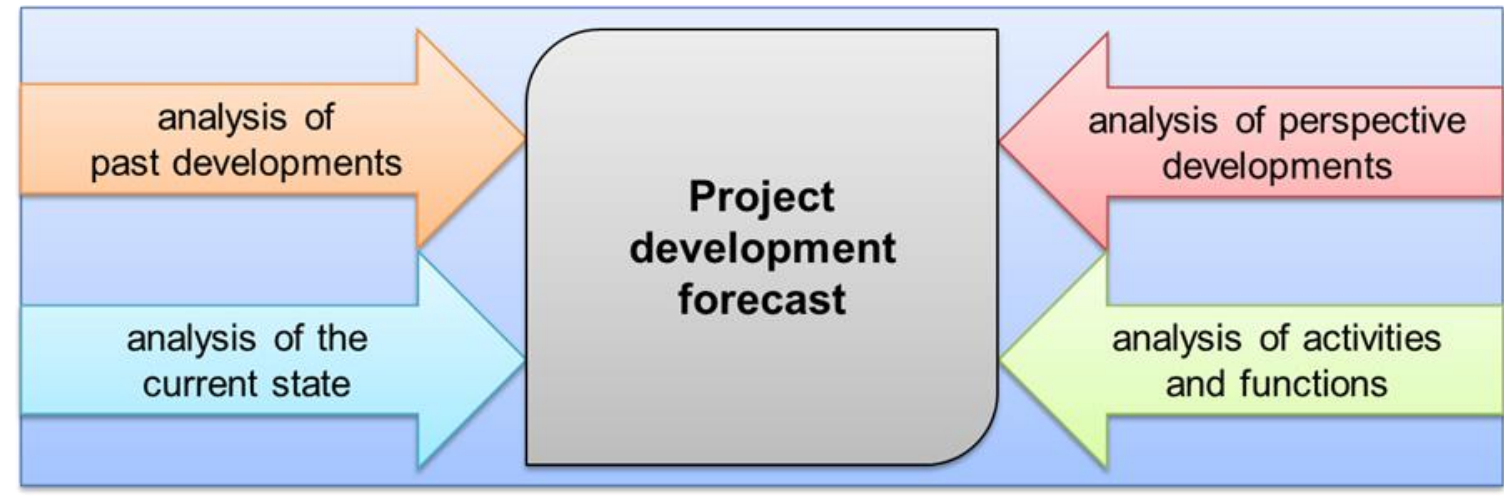

Figure 1: Processing forecasts and development concepts [Own design].

At present, such procedures are often used for the processing of forecasts and concepts of the required development of enterprises, but in the framework of research and development activities (projects), the collection and processing of this input information is very complicated due to the uncertainty of future activities.

\section{Materials and Methods}

In general, research and development are often solved by project activities, which by their nature are always unique, although they are more or less similar. For this reason, we are currently looking for project management options in the field of engineering that would eliminate these facts as much as possible. One of the possible aspects at present is agile methods for project management, which according to current literature and information from business practice are able to create an environment for effective and fast implementation and realization of ideas. These help to speed up the development process. Nevertheless, the initial steps are common to all projects, such as the basic design of a project plan, which is more of a framework nature for an agile project. For these activities, it is necessary to ascertain at the planning stage whether the resulting plan has any weaknesses and constraints that may limit the project in the future, and these must be assessed. For these reasons, it is desirable to have a system that has been able to identify and optimize these limits into a form that could be used in engineering project management in general. In these cases, it is not a risk assessment that should be part of the realization of each project offer, but evaluation or comparison of the requested project with projects that are generally performed in the company. In this way, the company is then able to eliminate the risks associated with project activities and processes, which can achieve the optimization of the planned project. These are processes and activities related to the company and its implementation in this company, which are in a certain direction repeatable and therefore from this perspective measurable and comparable. If such features are identifiable and it is possible to create key indicators from these, it is also possible to achieve some optimization of project processes in the company.

Uncertainty, risk, and rework make it extremely challenging to meet goals and deliver anticipated value in complex projects, and conventional techniques for planning and tracking earned value do not account for these phenomena. [1]

Because the value of the indicator is crucial for their effective use, it is necessary to specify the indicators that can influence engineering projects, paying maximum attention and effort. 
Furthermore, because the indicators are only certain models of reality and thus display the resulting information in a simplified way, it is necessary to evaluate the results and interpret them in a more comprehensible form, i.e. to describe not only the results of these indicators but also their links. Subsequently, we are able to ensure the effective use of such indicators, which is necessary for optimal planning in engineering projects.

Developed planning tool, like the process model, provides a framework for describing the costs and benefits of the activities and supplies involved in the process. The structure of the network of activities, including the supply flow, characterizes the process architecture. Each plan has a characteristic architecture, which is important for knowledge and accurate development prediction. [2]

The architecture could be found by the developed tool, but first must be designed a system of project profiles that we could use for it. With some kind of project profiles, we will be able to sort the projects and focus on the project management in the way which the company needs.

The objective of the planning of engineering changes is to create a plan for the implementation of the selected changes in the available time. For the planning of engineering changes, it has to be investigated which conditions are required to implement engineering changes parallel or in sequence. [3]

Project success depends on many factors, and context is one of them. Formal project planning and control system includes planning, measuring, and monitoring functions that enable the development of project plans and the comparison between the planned project objectives and the actual project performance. [4]

Despite this, plan creation is often undervalued for many reasons, but where there is no plan, nothing can be managed. And if the plan can be compared to reality, there is a high probability that the plan will be more accurate.

\section{Results and Discussions}

For the relevant project evaluation, it is often used in the project triangle, which is the basic block for project evaluation in terms of necessary inputs and required outputs. A project triangle is a tool by which we are able to evaluate the individual factors that affect the project and thus determine the resulting project quality. This functional indicator is therefore of external nature. This means that based on the time, re-source and functionality factors required by the customer, we are able to evaluate the resulting project quality or inform the customer of the expected project results. However, the project triangle indicator also has internal impacts. Therefore, according to the customer's requirements, we are able to identify in advance to what extent the individual factors will affect the company in this implementation, especially the deadlines, costs, etc. Unfortunately, this tool/indicator is so general that it is not able to quantitatively assess the input data and provide relevant and comprehensive information about the possible project characteristics or its possible expected development. Such a restriction is very important not only in practice. Therefore, in order to be able to objectively evaluate projects, it is necessary to create a system of indicators that can 
evaluate such projects. A possible solution to this situation is the presented model of several factors that can evaluate the project in a relevant, objective and comprehensive way.

Key indicators for evaluating the engineering project plan were compiled based on the possibility of their comparison, as well as the resulting regression and correlation relations. The basis for the evaluation was the assumption of possible theoretical and practical use, the ability to reliably evaluate the project plan and the possibility to follow this output during the implementation process. The result of this research is a tool where eight key indicators have been compiled. These selected functional indicators are the most important to identify and evaluate not only the project results but especially the project plan already at the stage of the bidding process, which is crucial for ensuring the efficiency of the requested projects. These eight key indicators include:

1) The functional effectivity of the project

2) The functional strength of the enterprise

3) Functional cost of the project

4) Functional project workload

5) The functional profitability of the project

6) The error rate on the project

7) The functional technical complexity of the project

8) Functional claiming of the enterprise

Each of these indicators has important characteristics that are important to assess, but they also interact with each other as a whole.

To present these indicators, it is first necessary to mention the current situation.

In general, engineering companies that implement development projects have their own business strategies. These strategies are more or less focused on both the business itself and the customer. In this case, we are interested in internal evaluation, that is, the company focused on internal processes and activities related to project planning and implementation. In these cases, the company is often only three basic measurable indicators.

Achieve the maximum workload of workers. In this case, it is the ability of the company to sell the customer's gained know-how or the necessary capacity that the customer lacks at the initiated time. This functional indicator is related to the performance of the company and the ability to get enough orders. The company's performance indicator is also often mentioned in terms of its market position and thus its size in relation to its competitors.

The last often highly desired measurable indicator is the profitability of the project, which is often mentioned with the overall comprehensive evaluation of the company and its success on the market in terms of competitive struggle or in terms of the price of the company.

The above-mentioned indicators are one of the most important and most frequently compared not only in the environment of engineering companies. For this reason, the proposed system of several indicators for evaluating the plans of these projects was created. 


\section{The Functional Effectivity of the Project}

The effectivity of the project is a complex indicator. This one can be characterized as the evaluator of the ability of the company to manage the project at sales and hours spent areas.

The first sales area is designed as a ration of all paid sales on the project towards the original order (order volume). The result is an indicator in which one gives us information about the ability of the company to claim all over-work or at least the original order. This indicator is crucial for relevant appreciation of the company's abilities in the sales area. If the abilities as a sales contract or project management fail than could jeopardize the whole project. A relationship with a customer could be endangered and all following cooperation could be canceled before the project finish. This state is failing not even for the project as a result which will not be finished properly, but as a company fails. So, this indicator is an information point where we could measure how company pro-cessing the projects and if they are efficient.

Hour ratio is the second part of the project efficiency indicator which one is on $\mathrm{X}$-axis. This part is important same as the Y-axis (sales) part because we need to know if the ordered volume of work was spent. The $\mathrm{X}$-axis part is the ratio of all spent hours on the project to-ward the original order.

The whole indicator is designed as a comparator of sales and hours towards their original orders. So with this indicator, we are able to evaluate how much the project is efficient in sales area and work area. These two areas are strongly connected because in engineering companies the major part of the work is based on hours (work) of the specialists. The indicator is capable to inform us about abilities to claim whole ordered volume (financial part) and worked not more than is ordered. Also, this indicator informs us about the overwork on the project and the capability of the company to claim all overworked hours (see on graph 1.).

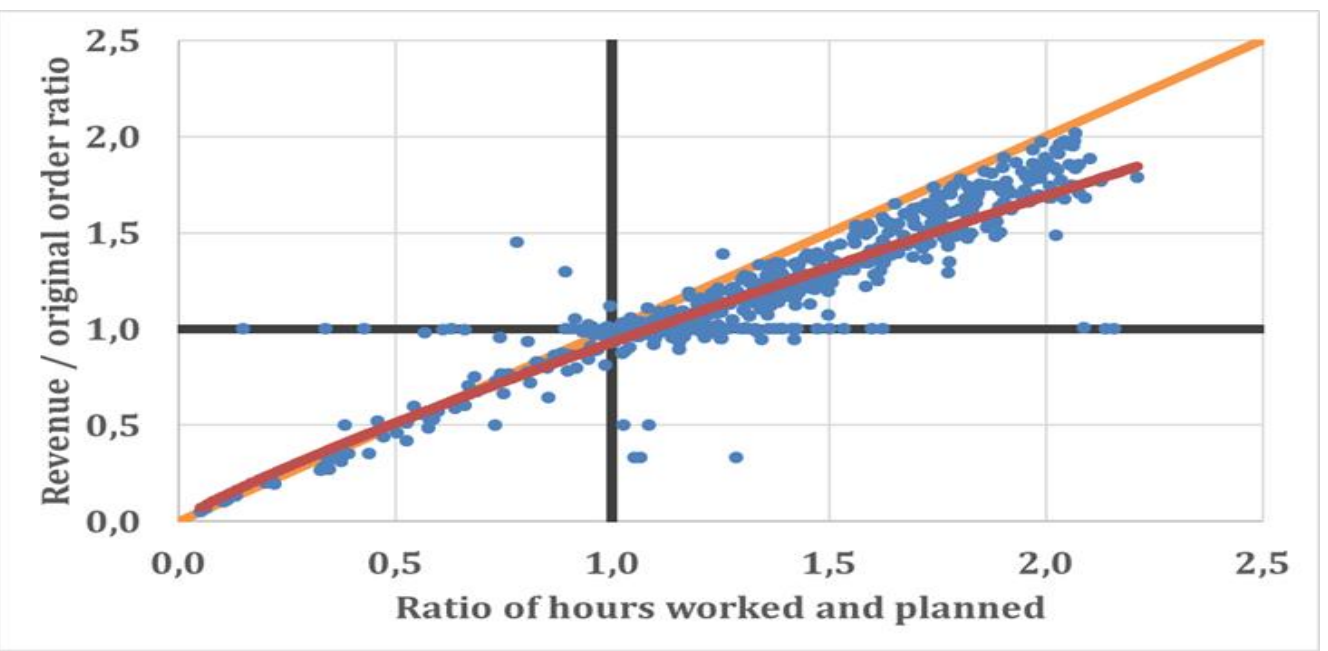

Graph 1: Indicator the functional effectivity of the project [Own design].

The result of this indicator is a complex view of the project management process on financial (sales) and non-financial (hours) areas. This complex view is important for the company as an indicator of abilities of the company where wastes in project management areas are. From the graph above we could state that at projects which are finished earlier, the engineering companies 
are capable to claim the whole volume of original order sometimes even a little bit more. On the other hand on projects which are overworked the company is not capable to claim at least the original order. So, companies should be focused on this area of project management in the engineering environment, this will be key to avoiding waste.

The function of projects effectivity is:

$\mathrm{y}=\llbracket 0,9309 \mathrm{x} \rrbracket \wedge 0,8625$

The resulting value of the correlation dependence (determination coefficient) is:

$\mathrm{R}^{\wedge} 2=0,8479$

This means that the accuracy of the function is $84.8 \%$. From the graph, we also could state that the major part of the projects is managed badly.

This indicator will be used in practice as a first part of the process for possible deviation management of the sales and hours on the planned projects. The next part will be the complex evaluation of the project according to the developed eight indicators.

\section{The Functional Strength of the Enterprise}

The strength of a company is an indicator that can be characterized as an evaluator of the strength of a company in the process of evaluating a given engineering project. It is, therefore, a ratio of possibilities or abilities of the company to negotiate better conditions of the planned project with the customer. When planning a development project, the resulting values are compared with the created tool, which can evaluate and categorize them. In this case, they are the values of the resulting financial offer of the project and the overall schedule of project hours that would be handed over to the customer as an offer. These input values are entered into the created tool and compared to the actual values. The values of the tool are created based on the implementation of the outputs of the given engineering projects. The original inputs include the total amount of invoicing on individual implemented projects and the sum of hours worked on these projects. This value is mainly influenced by the hourly rate of the company and the ability of the company to invoice all hours spent on the project.

The planned project is displayed as a point in the graph. The planned value $\mathrm{X}$ (the schedule of all hours needed for project implementation) has for each value on the X-axis the planned value $\mathrm{Y}$ (the value of the offer for the customer). Not only from the resulting graph is it possible to read the status of the planned project and its deviation within the evaluation of the project plan. The curve defining the boundary state where the evaluation of the project goes from sufficient to an insufficient state is expressed by the function:

$y=\llbracket 29,642 x \rrbracket \wedge 0,9828$

This function has validity interval

$\mathrm{x} \in<0 ; 7340>$. 
$\mathrm{Yi}=$ real value of sales from development projects

$\mathrm{Xi}=$ values of hours actually worked on projects

The resulting value of the correlation dependence (determination coefficient) is:

$\mathrm{R}^{\wedge} 2=0,986$

which means that $98.6 \%$ of the changes in the dependent variable are explained by the chosen regression function. The value of the correlation coefficient $\mathrm{R}$ was determined as follows:

$R=r=\sqrt{ }\left(R^{\wedge} 2\right)=\sqrt{ } 0,986=0,9929$

Hence the correlation coefficient shows a strong degree of functional dependency tightness when evaluating the dependency relationships of an enterprise-strength indicator.

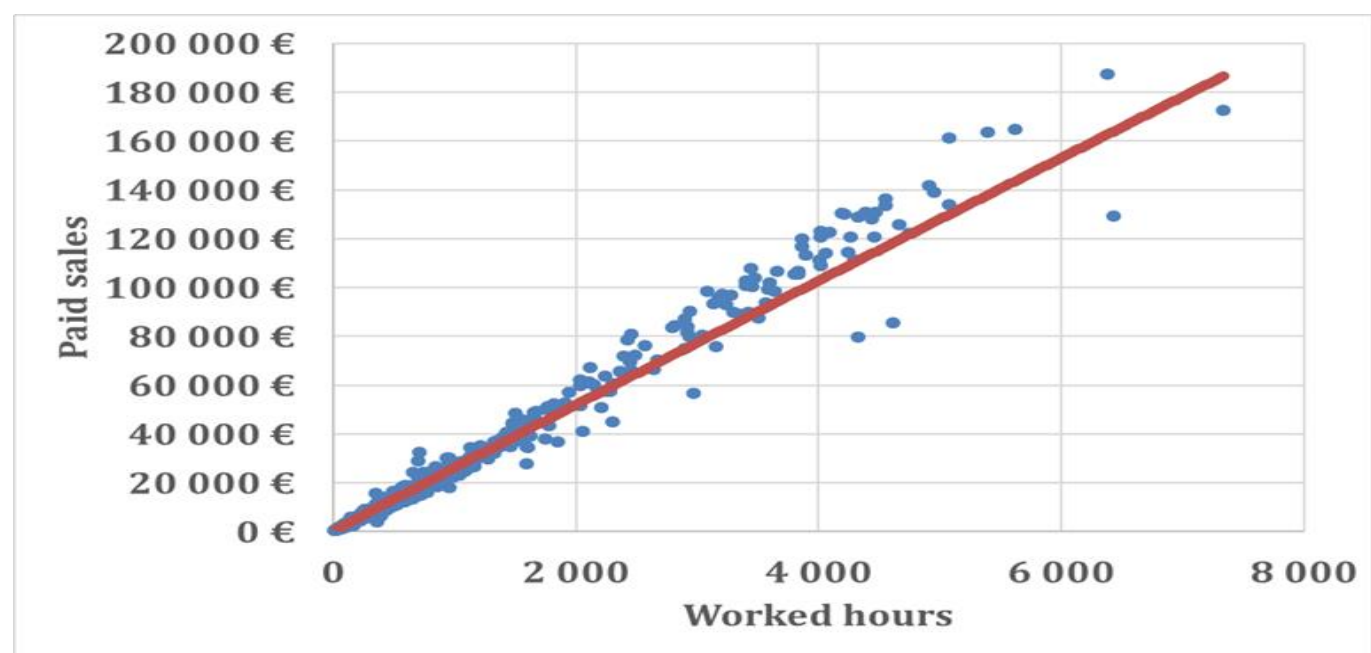

Graph 2: Indicator of the strength of the enterprise [Own design].

Several facts can be observed from the graph and the resulting function. The red curve, which indicates the function of the dependence of paid sales on the number of hours worked, is a power function. This function by its very least-squares method determines the course of the function, which can be characterized as a transition boundary or indicator when the strength of the company changes from insufficient strength of the company to sufficient. In this case, it can be stated that all projects that are below the curve of a given function are not sufficient from the company strength indicator and could or even should be improved in terms of the observed indicator. Furthermore, from this function and its character, we can state that the function of power character points to a very slight degressive behavior of this indicator. Thus, the fact those projects up to about four thousand hours tend to increase the strength of the company and projects greater than about four thousand hours are characterized by rather less firm strength, which is evident from the graph.

As a result of observing this indicator, we are not only able to characterize a certain course of the project at the planning stage and the possible projection of the project plan into this indicator, but it is also possible to characterize possible conditions for improvement. For example, it would be possible to set up business strategies aimed at improving the knowledge of project managers in 
larger projects, or at finding new tools for managing larger projects, etc. But this must be discussed and set at the top management level.

It was necessary to logarithmize the data in order to objectively verify the relevance of the data and thus the overall resulting model. The resulting function:

$\log ($ project billing $)=\llbracket 2,2614 * \log ($ sum worked hours $) \rrbracket \wedge 0,6099$

This function has validity interval $\mathrm{x} \epsilon\langle 1,1 ; 3,9\rangle$.

The resulting value of the correlation dependence (determination coefficient) is:

$\mathrm{R}^{\wedge} 2=0,9788$

Hence the logarithmize correlation coefficient shows a strong degree of functional dependency tightness when evaluating the dependency relationships of the enterprise-strength indicator.

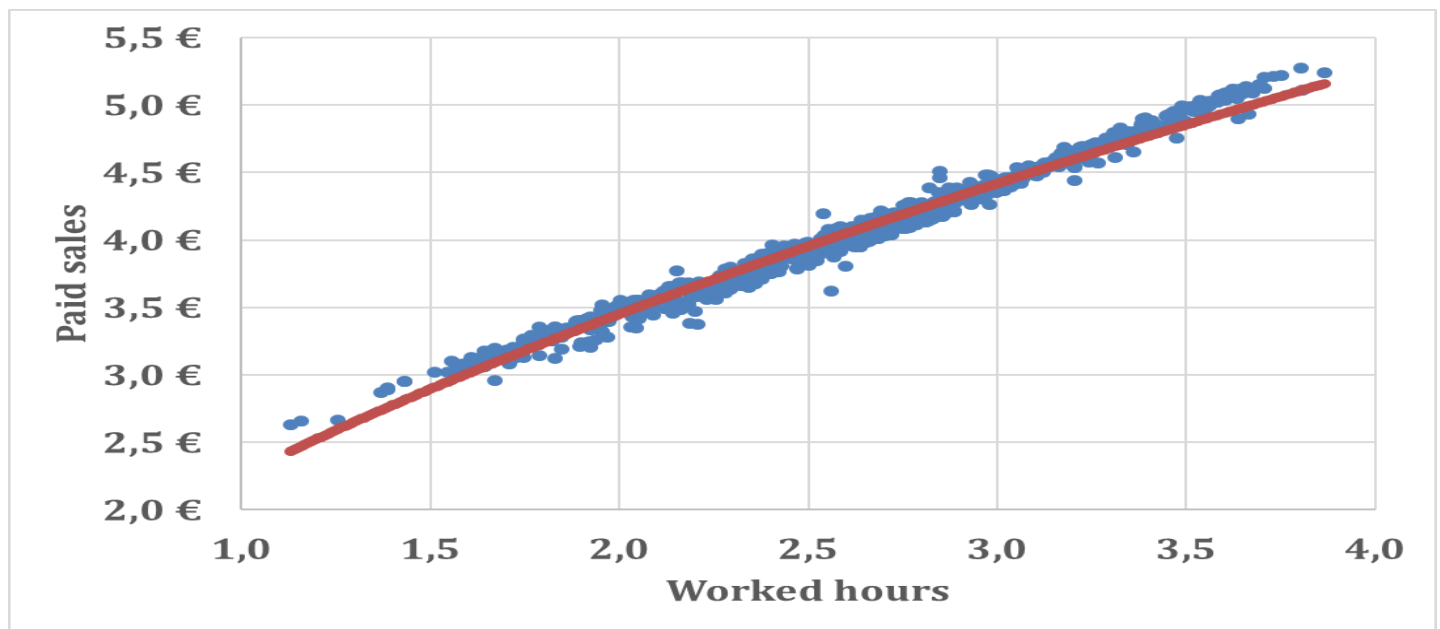

Graph 3: Logarithmize enterprise-strength indicator [Own design].

\section{Functional Cost of the Project}

In a simplified view, this indicator is the ratio of the volume of costs that are spent on a certain amount of revenue. Therefore, these are costs per unit of sales. The value of the cost ratio carries information about the necessity to incur a certain amount of costs that the project in the implementation of such a project we have to incur to obtain a certain volume of sales, which due to the characteristics of the function of evaluated projects has a slightly progressive character. In these cases, the resulting indicator gives us information on the development of costs according to the size of the project. As with the strength of the company, this is an indication that engineering companies are able to manage small projects efficiently, but as the project volume increases, its cost increases more progressively.

The resulting equation is:

$y=\llbracket 0,3336 x \rrbracket \wedge 1,0605$ 
Where correlation dependence is:

$\mathrm{R}^{\wedge} 2=0,9864$

The result is a very strong correlation dependency, which tells us information that about $98 \%$ of the results are explained by this function. This gives us information about accuracy which we could use to the prediction of the project in the cost area.

\section{Functional Project Workload}

The laboriousness intensity indicator of the project is a ratio indicator of the hours' plan and the hours worked. This indicator thus gives us information about the skills of project managers who manage projects in the company or about the overall project management process and its demands. The resulting function is slightly progressive, which gives us similar information regarding poor project management of large projects. For a more relevant assessment of the situation, further subdivision of projects and more detailed analysis is required.

The resulting equation is:

$\mathrm{y}=\llbracket 1,1055 \mathrm{x} \rrbracket \wedge 1,0114$

Where correlation dependence is:

$\mathrm{R}^{\wedge} 2=0,885$

Like the previous one, the equation here is strong correlation too. The coefficient of the correlation has $88 \%$ accuracy and that means that $88 \%$ could be explained by this function.

\section{The Functional Profitability of the Project}

This indicator is the ratio of the project margin that could be obtained in proportion to a certain amount of project revenue. It is, therefore, a margin per unit of revenue. The value of the margin ratio carries information about the project's ability to achieve or not meet certain requirements, in this case at least the limit of the resulting function. The ability to achieve the required margin is often not related to the volume of the project and therefore the environment in which the projects are implemented does not reflect the possibilities that projects in the business environment could achieve. The resulting function, which was created on the basis of all evaluated projects, is of a slightly degressive nature. This situation gives us basic information about the poor management of large projects, where project management should focus on collecting and processing the resulting engineering project data. Similarly to the indicator of the strength of an enterprise, the information is that engineering companies are able to manage small projects efficiently, but with increasing project volume their profitability decreases.

The resulting equation is:

$\mathrm{y}=\llbracket 0,508 \mathrm{x} \rrbracket \wedge 0,9428$ 
Where correlation dependence is:

$\mathrm{R}^{\wedge} 2=0,9618$

The coefficient of the correlation has $96 \%$ accuracy.

\section{The Error Rate on the Project}

The indicator shows the amount of planning errors on the project, which are expected according to the average corporate or team error rate. In this way, we are able to make a relevant assessment of what measures will be needed. That is, whether the number of predicted errors will not endanger the smooth planned course of the project. The volume of errors is, therefore, information that an enterprise can count on in the case of a project plan. However, this information and follow-up measures are key to the necessary adjustment of project costs and the calculation of the necessary measures that reduce or eliminate the planned error rate to a minimum. The costs associated with the measure are necessary in these cases, otherwise, there may be situations where the customer is so dissatisfied with the resulting quality of work that, in extreme cases, can withdraw from the contract and terminate the project prematurely. In the best case, the costs associated with overwork are often not included in the revenues and thus reduce the profitability of the project. This may result in irrelevant project plans and costs and thus erroneous development predictions. Of course, there is also the possibility of further development of the error rates, especially in terms of financial assessment of errors. Such a financial assessment of errors and the determination of the value of errors would result in further refinement, but in the current business situation, this situation is not checked and recorded. This element could be part of further improvement of the whole system, which would allow the possibility of accurate financial evaluation of errors and their exact impact on costs according to the weight (financial value) of individual errors. Consequently, it could be assessed whether the amount and value of the error rate, i.e. the total cost of errors, have higher costs than the planned measures. Unfortunately, it is not possible to find out from the currently available data. In the current state, the error rate on projects is defined by the equation below.

The resulting equation is:

$\mathrm{y}=\llbracket 0,1163 \mathrm{x} \rrbracket \wedge 0,9312$

Where correlation dependence is:

$\mathrm{R}^{\wedge} 2=0,8478$

The correlation coefficient still has a strong degree of functional dependency tightness where at least $84 \%$ could be explained by this function.

\section{The Functional Technical Complexity of the Project}

The indicator is a representation of the volume of scheduled hours on a project that is expected to be spent on processing a certain amount of elements on a project. It is, therefore, a certain amount of hours per average unit of a task to be completed. The value of the hours required to process the 
element carries information about the ability of the project team to achieve or not meet the required technical requirements. In this case, at least the boundary of the resulting function, this characterizes the complexity of engineering projects. The ability to reduce the demands on the required amount of elements is often not related to the project volume but is about the capabilities of the company and the team where the projects are implemented. The resulting function, which was created on the basis of all evaluated projects, is a slightly degressive nature. This state gives us information about the frequent planning of large engineering projects with fewer hours. Project analysis should identify weaknesses in project management and develop corrective actions. However, in the current state, it can be stated that the possible cause of the degressive behavior of functions of the strength of the company and the profitability of the project is the hourly underestimation of the projects, which consequently leads to a decrease in the profitability of these larger projects. Although technical complexity is an indicator that takes into account rather the technical input of projects, there are some links to financial indicators such as profitability. A possible cause of underestimation of larger projects may be the fact that the company is poor in negotiating larger contracts, which may be associated with the uncertainty of the management of the company whether such projects are able to complete in the required scope and quality.

The resulting equation is:

$\mathrm{y}=\llbracket 19,917 \mathrm{x} \rrbracket \wedge 0,9219$

Where correlation dependence is:

$\mathrm{R}^{\wedge} 2=0,8915$

The coefficient of the correlation still has a strong degree of functional dependency tightness where at least $89 \%$ are explained by this function. This gives us information about accuracy which we could use to the prediction of the project in tasks technical complexity.

\section{Functional Claiming of the Enterprise}

The claim indicator is a ratio of the original order to all paid sales for projects. This indicator gives us information about the capabilities of project managers, salesmen, and top management, how they are able to manage and claim scheduled as well as unplanned services. The resulting function is slightly progressive, which gives us information regarding poor project management of small and medium projects. However, this situation is difficult to assess reliably only on the basis of these data, mainly because of the large number of small and medium-sized projects. For a more relevant assessment of the situation, further subdivision of projects and more detailed analysis is required.

The resulting equation is:

$y=\llbracket 1,0494 x \rrbracket \wedge 1,0041$

Where correlation dependence is:

$\mathrm{R}^{\wedge} 2=0,8962$ 
The logarithmize correlation coefficient shows a strong degree of functional dependency tightness when evaluating the dependency relationships of the enterprise-strength indicator.

For over a decade, Flyvbjerg has examined the causes of failures in project planning and concluded that a large number of projects suffer from the joint and combined effects of delusion and deception on the part of the project organization and its principal stakeholders. That is, delusion is often the result of adopting an inside view of the project: focusing only on the plan itself, the obstacles that have to be overcome, the scenarios to consider, and current trends to uncover. The inside view is a bottom-up decision-making process that dis-counts the wealth of historical data, past experiences, and environmental factors that are likely to affect the project. [5]

As reported by the U.S. Government Accounting Office (www.gao.gov/assets/120/117799.pdf), over $70 \%$ of U.S. IT projects are poorly planned and/or underperforming. Although equally extensive data on non-IT projects are less available, many large and complex design, development, and construction projects have also exhibited high-visibility problems-for example, the F-35 aircraft (e.g., IDA, 2010), Boston's Central Artery Tunnel (the "Big Dig"), and Denver International Airport (e.g., Calleam, 2008), just to mention a few.[1]

Project management is a major part of the process of creating a value of product development, but even more important is accurate project plan making. That is why the most important part which should be focused on is knowledge about project planning and project management. This new method could help with this task. The knowledge about how engineering projects will evolve is key for a more accurate project plan and better project management. Knowledge of the environment and the ability to predict project development is important not only for the involved company.

Similar to the article A Quantitative Framework for Managing Project Value, Risk, and Opportunity from Mr. Tyson R. Browning the input for each indicator includes $\mathrm{n}$ attributes.

Citation: "The value of a project outcome can be modeled as a vector, $\vartheta$, of n value attributes, $\phi . "$ [6]

During the development of the engineering plan evaluation tool, the individual indicators are a set of more inputs/attributes. Each indicator is formed by the function of the attributes. This function is key for knowledge for engineering project management environment and the main part for the optimization of the project planning. Each indicator is focused on a different area and the whole system creates a complex view on project planning.

From the regression and correlation evaluation of the dependency relationships of the engineering projects of the individual created indicators it can be observed that all values of the evaluated indicators found high values of correlation coefficients and determination coefficients. The determined values of determination coefficients show that for all indicators the changes of the dependent variable are mostly explained by the chosen regression function.

These for better clarity can be divided into two basic groups, namely financial and non-financial (technical). This breakdown of these indicators is rather of an informative nature, although the 
indicators have financial and non-financial characteristics, it is not possible to clearly classify these indicators into these groups because of the large number of attributes that affect them.

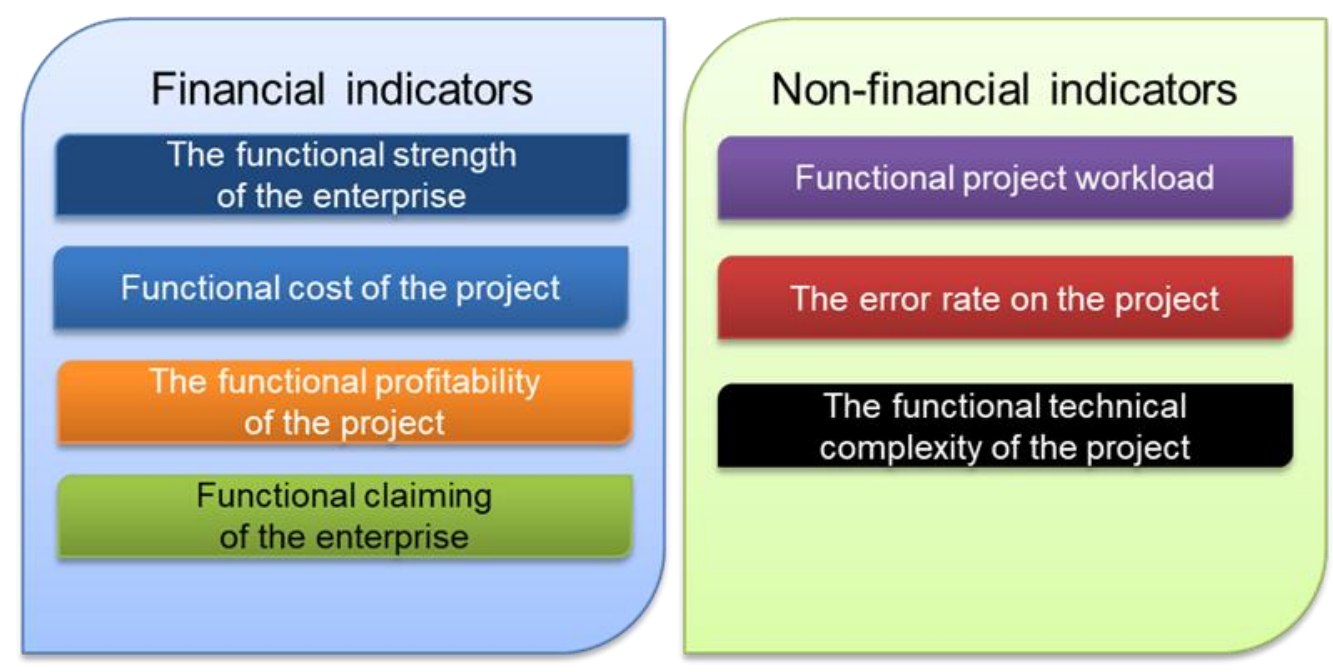

Figure 2: Distribution of developed indicators [Own design]

With the help of this system and the ability to detect the behavior of the whole system, it is possible to draw from this knowledge the knowledge necessary to ensure certain corrective actions, but also about the categorization of projects and characterization of these groups. With this selection of project management, it is possible to further study the characteristics and course of processes that are very significant and otherwise, their behavior could not be studied. It is therefore also possible to develop different procedures and measures for each project group, which may differ significantly.

\section{Conclusions and Recommendations}

This tool generally helps to reduce waste, but further development of the system can not only optimize but also provide new knowledge about the system.

The whole system is developed on the database of about seven hundred engineering projects, which are finished in different engineering companies. This gives us evidence of results and developed indicators equations.

Resulted state from the functional effectivity of the project is that about $94 \%$ of the projects are still managed wrongly. The functional effectivity of the project is one of the indicators which one is crucial for a fast and deep review of the current state of the project management in the engineering company. This one indicator could help to identify the core of the problems in the company in the area of project management. Through the whole developed system, these deficiencies can be identified more precisely and the whole planning process can be optimized before the project is approved. Within the know-how of the project management characteristic of the created indicators, we are able to the relevant evaluation of the plan before we send created plan to the customer. That is the advantage that engineering companies should use if they want to improve their project management skills. An overview of the pros and cons in each indicated area 
will not only lead to a better knowledge of the environment but also the possibility of early intervention and modification of the plan. Also, the possibility of more accurate predictions of the plan will be an advantage.

\section{Acknowledgments}

This work was supported by the Grant Agency of the Czech Technical University in Prague, grant No. SGS17/178/OHK2/3T/12

\section{Appendices}

Regression analysis allows us to determine the form of dependence and to express it by the socalled regression function regression problem.

Correlation analysis helps to determine the degree of strength with which a given dependence manifests itself in the middle of various interfering side factors - the correlation task.

\section{References}

[1] BROWNING, Tyson R. Planning, Tracking, and Reducing a Complex Project's Value at Risk. Project Management Journal [online]. 2019, 50(1), 71-85. ISSN 8756-9728. Dostupné z: DOI: $10.1177 / 8756972818810967$

[2] BROWNING, Tyson R. On customer value and improvement in product development processes. Systems Engineering [online]. 2003, 6(1), 49-61. ISSN 1520-6858. Dostupné z: DOI:10.1002/sys.10034

[3] Support of Engineering Changes in Manufacturing Systems by Production Planning and Control Methods | Elsevier Enhanced Reader [online]. [vid. 2019-09-21]. Dostupné z: DOI:10.1016/j.procir.2015.12.049

[4] MARIER-BIENVENUE, Thierry, Robert PELLERIN a Luc CASSIVI. Project Planning and Control in Social and Solidarity Economy Organizations: A Literature Review. Procedia Computer Science [online]. 2017, 121, CENTERIS 2017 - International Conference on ENTER-prise Information Systems / ProjMAN 2017 - Internatio-nal Conference on Project MANagement / HCist 2017 - International Conference on Health and Social Care In-formation Systems and Technologies, CENTE-RIS/ProjMAN/HCist 2017, 692-698. ISSN 1877-0509. Dostupné z: doi:10.1016/j.procs.2017.11.090

[5] PINTO, Jeffrey K. Lies, damned lies, and project plans: Recurring human errors that can ruin the project planning process. Business Horizons [online]. 2013, 56(5), 643-653. ISSN 0007-6813. Dostupné z: doi:10.1016/j.bushor.2013.05.006

[6] BROWNING, T. R. A Quantitative Framework for Managing Project Value, Risk, and Opportunity. IEEE Transactions on Engineering Management [online]. 2014, 61(4), 583-598. ISSN 0018-9391. Dostupné z: doi:10.1109/TEM.2014.2326986

*Corresponding author.

E-mail address: jan.lhota@ fs.cvut.cz 